\title{
Typen erotus ja talteenotto lantaperäisestä nesteestä
}

Ervasti Satu ${ }^{1)}$, Winquist Erika ${ }^{2)}$

${ }^{1)}$ Luonnonvarakeskus, Uudet liiketoimintamahdollisuudet, Tietotie 2, 31600 Jokioinen, satu.ervasti@luke.fi

${ }^{2)}$ Luonnonvarakeskus, Uudet liiketoimintamahdollisuudet, Viikinkaari 4, 00790 Helsinki, erika.winquist@luke.fi

\section{TIIVISTELMÄ}

Lannan prosessoinnin tavoitteena on yleensä fosforin erottaminen kiintojakeeksi, joka voidaan kuljettaa kauemmaksi. Samalla muodostuu kuitenkin typpeä sisältävää nestettä, jonka volyymit ovat suuria, mutta typpipitoisuudet varsin pieniä. Nesteessä oleva ammoniumtyppi voidaan erottaa ja konsentroida hyödyntämällä strippaustekniikkaa. Täsmätyppi-hankkeessa (YM Raki 2014-2015) tutkittiin ammoniumtypen talteenottoa sian lietelannasta peräisin olevalla nesteellä.

Ammoniumtypen talteenotossa prosessivaiheet ovat esikäsittely (lämmitys ja $\mathrm{pH}: n$ säätö), ammoniakin strippaus nestejakeesta kaasufaasiin ja ammoniakin pesu kaasufaasista vastaanottoliuokseen. Kokeissa käytettiin pilot-mittakaavan ammoniakin strippaus- ja talteenottolaitteistoa. Käsiteltävä neste oli peräisin sian lietelantaa käsittelevästä prosessista, jossa kiintoaineesta erotettu neste käsiteltiin aerobisessa mikrobiprosessissa. Nesteen kuiva-ainepitoisuus oli 0,5-0,8 \%, ammoniumtyppipitoisuus 1,2-1,3 g/l ja $\mathrm{pH} \mathrm{8,0-8,8.} \mathrm{Strippausta} \mathrm{varten} \mathrm{nesteen} \mathrm{pH}$ nostettiin halutulle tasolle käyttäen $50 \%$ natriumhydroksidia $(\mathrm{NaOH})$ ja neste esilämmitettiin $+40{ }^{\circ} \mathrm{C}$ :seen sähkövastuksilla. Stripperiin puhallettiin sisään huoneilmaa, joka johdettiin pesurin kautta ulos prosessista. Pesuriyksikössä kierrätettiin rikkihappoliuosta, jolloin pesutuotteena muodostui ammoniumsulfaattia.

Koeajot toteutettiin kahdessa erillisessä jaksossa, joiden välillä laitteistoon tehtiin parannuksia tavoitteena prosessiolosuhteiden optimointi ja sitä myötä tehokkaampi ammoniumtypen erottuminen. Ensimmäisellä koejaksolla käytettävissä oli kaksi eri virtausnopeutta nesteelle, 0,37 ja 0,76 1/min. Ilmavirtaamat olivat puolestaan 3,6-10,9 m3/h. Toisella koejaksolla nestevirtaamat olivat välillä 1-3 1/min ja ilmavirtaamat $13-24 \mathrm{~m} 3 / \mathrm{h}$. Tähän esitykseen on otettu mukaan vain toisen koejakson tulokset, joiden perusteella tarkasteltiin myös prosessin taloudellista kannattavuutta. Täsmätyppi-hankkeen tulokset julkaistaan kokonaisuudessaan alkuvuodesta 2016 Luonnonvarakeskuksen julkaisusarjassa.

Eri käsittelyolosuhteissa toteutetuissa kokeissa ammoniumtypen erotustehokkuudet vaihtelivat välillä 15-91 \%. Ilma/neste-suhde ja pH vaikuttivat odotetusti erotustehokkuuteen stripperissä; erottuminen tehostui, kun käytettiin suurempaa ilmanpuhallusta, pienempää nesteen virtaamaa ja nostettiin $\mathrm{pH}$ korkeammalle. Tehokkaimmillaan ammoniumtypen poistuma oli $92 \%$, joka saavutettiin pH:ssa 11,3 ja ilma/neste-suhteella 392.

Happopesurissa käytettiin panostyyppisesti samaa pesuliuosta koko koejakson ajan. Ammoniakin ja rikkihapon reaktiossa muodostuvaa ammoniumsulfaattiliuosta tuotettiin siis kaksi erää. Tuotteiden ammoniumtyppipitoisuudet olivat 15,3 ja 21,7 g/l, eli ammoniumsulfaatiksi laskettuina 7,2 ja 10,2\%.

Kokeista kerättiin tietoa käytössä olleen stripperilaitteiston erotustehokkuudesta, taloudellisuudesta ja käytettävyydestä. Kokeissa mitattiin prosessin energiankulutus sekä kerättiin tiedot kemikaalien $(\mathrm{NaOH}$ ja rikkihappo) kulutuksesta. Prosessoinnin kustannukset on laskettu sekä käsiteltävää nestetonnia että tuotettua typpikiloa kohti. Lisäksi kokeista saatiin käytännön kokemusta tekniikan toteutettavuudesta.

Asiasanat: ammoniakki, strippaus, ammoniumsulfaatti, typen talteenotto 


\section{Johdanto}

Suomessa käytetään maataloudessa epäorgaanista väkilannoitetyppeä noin 138 000-180 000 tonnia vuosittain (Eurostat). Tämä on noin $65 \%$ maatalousmaahan kokonaisuudessaan lisätystä typestä. Yhteensä Suomen maatalousmaahan lisätään typpeä vuosittain 276500 tN/a. Eläinten lannasta peräisin olevaa typpeä käytetään lannoitukseen vuosittain noin 66700 t. (Antikainen ym. 2005)

Maatilojen koon kasvu ja keskittyneet lannan käsittelylaitokset aiheuttavat lannan ravinteiden kertymistä tietyille alueille. Lannan prosessoinnin tavoitteena on yleensä fosforin erottaminen kiintojakeeksi, joka voidaan kuljettaa kauemmaksi. Samalla muodostuu kuitenkin typpeä sisältävää nestettä, jonka volyymit ovat suuria, mutta typpipitoisuudet varsin pieniä. Nesteessä oleva ammoniumtyppi voidaan erottaa ja konsentroida hyödyntämällä strippaustekniikkaa. Viljelijän kannalta olisi toivottavaa päästä eroon myös laimean nestejakeen kuljettamisesta. Tämä tavoite voidaan saavuttaa konsentroimalla typpi omaksi jakeeksi strippaamalla, jolloin jäljelle jäävä nesteosa voidaan levittää esimerkiksi sadettamalla lähipelloille ja konsentroitu typpiliuos voidaan levittää kauemmille pelloille kaupallisten mineraalilannoitteiden tapaan. Lannan prosessoinnilla voidaan parantaa typen käyttökelpoisuutta kasveille ja tarkentaa typpilannoitusta, mikä vähentää typen huuhtoutumisriskiä vesistöihin.

Typen kierrätys on perusteltua myös epäorgaanisten lannoitteiden valmistuksessa kuluvan suuren fossiilisen energian määrän takia. Suomessa käytetään tällä hetkellä maataloudessa epäorgaanisia typpilannoitteita 135 000-155000 tonnia vuosittain. Typpi sidotaan perinteisiin epäorgaanisiin lannoitteisiin maakaasulla tuotetun energian avulla ja kuljetetaan pääosin Venäjältä ammoniakkina Suomeen lannoitteiden valmistusta varten, joten typen kierrätyksellä voidaan lisätä Suomen typpiomavaraisuutta.

Ammoniakin strippaus on yleisesti tunnettu menetelmä, jota käytetään mm. väkevien jätevesien typen-poistossa (Cheung ym. 1997, Janus ym. 1997; Jardin ym. 2006). Se sopii hyvin aerobisesti ja anaerobisesti käsiteltyjen lannan ja biokaasulaitosten käsittely-jäännösten nestejakeiden prosessointiin, koska niiden liukoinen typpi on pääosin helposti haihtuvassa ammoniummuodossa. Strippauksessa ammoniumtyppi siirretään nesteestä kaasufaasiin ja otetaan talteen esimerkiksi happoliuokseen. Molemmat vaiheet tapahtuvat kolonneissa, joita kutsutaan strippaus- ja pesuriyksiköiksi.

Täsmätyppi-hankkeen (YM Raki 2014-2015) tavoitteena oli tarve kehittää ratkaisuja lannan sisältämän typen tehokkaammalle, täsmällisemmälle ja ympäristöä vähemmän kuormittavalle käytölle. Ammoniumtypen talteenottoa tutkittiin sian lietelannasta peräisin olevalla nesteellä pilot-mittakaavan ammoniakin strippaus- ja talteenottolaitteistolla. Stripperikokeissa etsittiin ammoniakin konsentrointiin optimaalisia pH ja lämpötilatasoja sekä käytettävän laitteiston kannalta optimaalisia ilma- ja nestevirtaamia, tavoitteena tuottaa mahdollisimman konsentroitua ammoniumtyppiliuosta. Pilot-kokeissa osoitettiin prosessin tekninen toimivuus, mutta suuri kemikaali- ja energiakulutus nosti kierrätystyppilannoitteen valmistuskustannuksia. Prosessi ei ole sellaisenaan kannattava, jos kannattavuutta tarkastellaan kierrätystyppilannoitteen valmistuksen kannalta. Sen sijaan tapauskohtaisesti prosessi saattaa olla kannattava, jos sen avulla pystytään laskemaan teollisen prosessin jätevesimaksuja esim. biokaasulaitoksen yhteydessä.

\section{Aineisto ja menetelmät}

Kokeissa käytettiin Luonnonvarakeskuksen (Luke) omistamaa pilot-mittakaavan ammoniakin strippaus- ja talteenottolaitteistoa. Sekä stripperi- että pesurikolonni olivat korkeudeltaan 4,3 m, josta täytekappalekorkeutta oli $2,45 \mathrm{~m}$. Stripperin sisähalkaisija oli $20,2 \mathrm{~cm}$. Stripperi- ja pesuritornissa oli molemmissa täytekappaleina $40 \mathrm{~mm}$ halkaisijan pall-renkaat. Käsiteltävä neste esilämmitettiin $+40^{\circ} \mathrm{C}$ :een ja neste pumpattiin stripperitorniin vain kerran, eikä nestettä kierrätetty tornissa. Stripperiin puhallettiin sisään huoneilmaa, joka johdettiin pesurin kautta ulos prosessista.

Käsiteltävä neste oli peräisin sian lietelantaa käsittelevästä prosessista, jossa kiintoaineesta erotettu neste käsiteltiin aerobisessa mikrobiprosessissa (Alitalo 2014). Nesteen kuiva-ainepitoisuus (TS) oli 5,4$8,2 \mathrm{~g} / \mathrm{kg}$ ja ammoniumtypen $\left(\mathrm{NH}_{4}-\mathrm{N}\right)$ pitoisuus 1,23-1,33 g/l. Kuiva-aineen (TS) ja orgaanisen kuivaaineen (VS) määritykset tehtiin standardin SFS 3008 mukaisesti. Ammoniumtyppi määritettiin suoralla kolorimetrisellä menetelmällä (McCullough 1967). Näytteet, lukuun ottamatta pesurin näytteitä, kestävöitiin heti näytteenoton jälkeen väkevällä rikkihapolla, jotta vältettäisiin säilytyksen aikaiset ammoniumtypen tappiot. Strippausta varten nesteen $\mathrm{pH}$ nostettiin halutulle tasolle käyttäen $50 \%$ natriumhydroksidia 
$(\mathrm{NaOH})$. Käsiteltäville nesteille tehtiin ennen strippauskokeita titraukset $\mathrm{NaOH}: 11$, jotta saatiin selville tarvittava annostelu varsinaisissa kokeissa, kun haluttiin $\mathrm{pH}$ tietylle tasolle.

Testattavana oli aiempien kokeiden sekä pumpun ja puhaltimen toiminta-alueiden puitteissa kuusi eri ilma/neste -suhdetta. Nesteen pumppausnopeudet olivat 1,2 ja $3 \mathrm{l} / \mathrm{min}$ ja ilman puhallus toteutettiin puhaltimella taajuuksilla 50, 70 ja $90 \mathrm{~Hz}$, vastaten keskimäärin ilmavirtauksia 13,$8 ; 19,0$ ja 23,6 m²/h. Kullakin olosuhdekombinaatiolla tehtiin kaksi toistoa. Lisäksi tehtiin koeajo täysin ilman pH:n nostoa (11 $70 \mathrm{~Hz})$ sekä kokeet kahdella ilma/neste -suhteella $(11,70 \mathrm{~Hz}$ ja 11, $90 \mathrm{~Hz})$ muihin ajoihin verrattuna korkeammalla pH:lla. Kokeen kestot vaihtelivat käytetyn nestevirtaaman mukaan, tavoitteena oli saada kullakin ajolla käsiteltyä noin 301 nestettä. Neste pumpattiin stripperiin epäkeskoruuvipumpulla (toiminta-alue noin 1-11 1/min). NaOH syöttö tehtiin automaattisesti halutulla \% -osuudella.

Samanaikaisesti ammoniumtypen erottumista stripperillä tutkittaessa tuotettiin happopesurilla konsentroitua typpiliuosta. Pesuriyksikössä kierrätettiin rikkihappoliuosta, jolloin pesutuotteena muodostui ammoniumsulfaattia. Pesuliuosta kierrätettiin pesurissa panostyyppisesti ja nestepanos oli koejakson alussa 30,51 .

\section{Tulokset ja tulosten tarkastelu}

\section{Pilot-mittakaavan ammoniakin strippaus- ja talteenottokokeet}

Ammoniumtypen pitoisuudet nesteessä strippauksen jälkeen olivat $0,11-1,12 \mathrm{~g} / \mathrm{l}$ lähtöpitoisuuden ollessa 1,23-1,33 g/l. Yksittäisissä ajoissa saatiin parhaimmillaan 91,9 \% erotustehokkuus ammoniakille. Nesteen pH oli tällöin nostettu yli 11 tasolle, nestevirtaus oli 1 1/min, puhaltimen käyttötaajuus $90 \mathrm{~Hz}$ ja ilma/neste-suhde 368. Strippauskokeiden tulokset kahden toiston keskiarvoina on esitetty taulukossa 1.

Taulukko 1. Keskiarvot kahdesta toistosta eri käsittelyillä

\begin{tabular}{|c|c|c|c|c|c|c|}
\hline $\begin{array}{l}\text { nestevirtaama } \\
\text { minuutissa, } \\
\text { ilmavirtaaman } \\
\text { voimakkuus }\end{array}$ & $\begin{array}{l}\mathrm{NH}_{4}-\mathrm{N}- \\
\text { pitoisuus } \\
\text { alussa } \\
(\mathrm{g} / \mathrm{l})\end{array}$ & $\begin{array}{l}\mathrm{NH}_{4}-\mathrm{N}- \\
\text { pitoisuus } \\
\text { lopussa } \\
(\mathrm{g} / \mathrm{l})\end{array}$ & $\mathrm{pH}$ & $\begin{array}{l}\text { sisään } \\
\text { menevän } \\
\text { nesteen } \\
\text { lämpötila } \\
\left({ }^{\circ} \mathrm{C}\right)\end{array}$ & $\begin{array}{l}\text { ilma/neste } \\
\text {-suhde } \\
\text { (1/l) }\end{array}$ & $\begin{array}{l}\text { erotustehokkuus } \\
(\%)\end{array}$ \\
\hline $11,50 \mathrm{~Hz}$ & 1,30 & 0,43 & 10,30 & 35,5 & 251 & 66,9 \\
\hline $11,70 \mathrm{~Hz}$ & 1,30 & 0,38 & 10,49 & 38,0 & 302 & 71,2 \\
\hline $11,90 \mathrm{~Hz}$ & 1,30 & 0,32 & 10,41 & 38,6 & 418 & 75,8 \\
\hline $21,70 \mathrm{~Hz}$ & 1,30 & 0,60 & 10,00 & 39,4 & 168 & 54,2 \\
\hline $21,90 \mathrm{~Hz}$ & 1,30 & 0,56 & 10,15 & 35,3 & 218 & 57,3 \\
\hline $31,90 \mathrm{HZ}$ & 1,23 & 0,72 & 9,57 & 38,1 & 139 & 41,5 \\
\hline $1 \mathrm{l}, 70 \mathrm{~Hz}$, ei pH nostoa & 1,33 & 1,12 & 8,42 & 37,8 & 340 & 15,5 \\
\hline $11,70 \mathrm{~Hz}, \mathrm{pH}$ korkea & 1,24 & 0,14 & 11,81 & 39,9 & 321 & 88,7 \\
\hline $11,90 \mathrm{~Hz}, \mathrm{pH}$ korkea & 1,24 & 0,11 & 11,30 & 39,7 & 392 & 91,5 \\
\hline
\end{tabular}

Ammoniumtypen erotustehokkuus nousi ilma/neste -suhdetta kasvatettaessa ja pH:n noustessa. Kuuden ensimmäisen käsittelyn erotustehokkuudet on esitetty ilma/neste -suhteen funktiona kuvassa 1. 


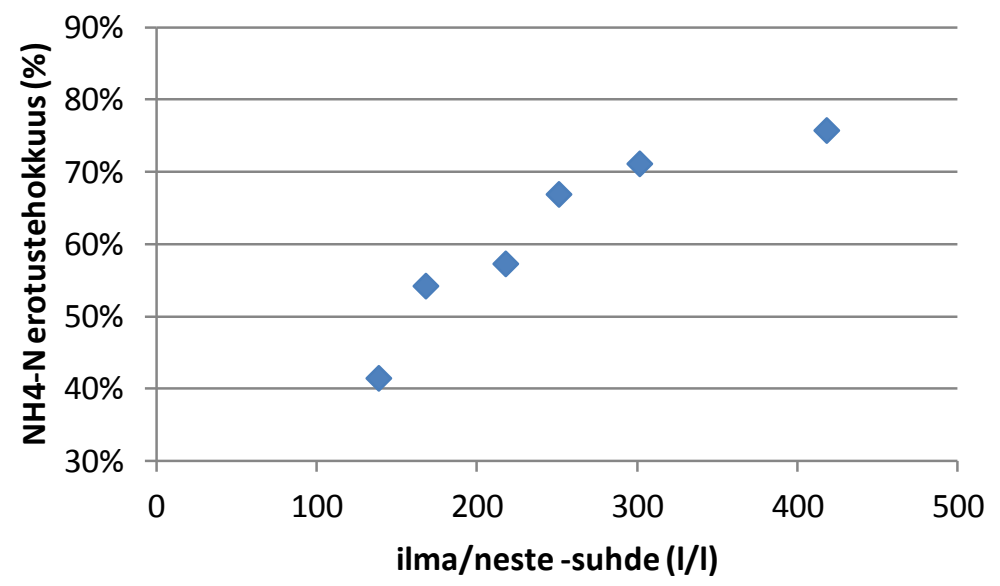

Kuva 1. $\mathrm{NH}_{4}-\mathrm{N}$ erotustehokkuus ilma/neste -suhteen funktiona, käsiteltävän nesteen $\mathrm{pH}$ 9,6-10,5.

Samanaikaisesti, kun tutkittiin ammoniumtypen erottumista stripperillä, tuotettiin happopesurilla konsentroitua typpiliuosta, ammoniakin ja rikkihapon reaktiossa muodostuvaa ammoniumsulfaattiliuosta. Pesuliuosta kierrätettiin pesurissa panostyyppisesti. Pesuliuoksen ammoniumtyppipitoisuus koejakson jälkeen oli 15,3 g/l, eli ammoniumsulfaatiksi laskettuna $72 \mathrm{~g} / \mathrm{l}$. Lannoituskäyttöä ajatellen tuotteen typpipitoisuus oli matala.

Syitä alhaisiksi jääneille ammoniumtypen pitoisuuksille pesuliuoksessa olivat $\mathrm{mm}$. käsiteltävän nesteen alhainen ammoniumtyppipitoisuus (1,2-1,3 g/l), stripperin pienet nestevirtaamat (1-3 1/min) ja heikko erotustehokkuus stripperissä osalla käsittelyillä. Näin ollen useankin viikon koeajojen aikana pesurille kertyvä ammoniumtypen määrä jäi vähäiseksi.

\section{Kierrätystyppilannoitteen valmistuskustannus ja prosessin kannattavuus}

Ammoniumsulfaatin valmistuksen suurimmat kustannukset ovat energia- ja kemikaalikustannukset. Näiden perusteella laskettiin minimituotantokustannus, joka ei huomioinut laitteiston investointikustannuksia eikä työaikaa. Ammoniumsulfaatin valmistuskustannuksen laskentaan käytetyt energian ja kemikaalien hintatiedot on annettu taulukossa 2. Pilot-prosessin mittakaava vastaa maatilamittakaavaa.

Taulukko 2. Laskuissa käytettyjä energian ja kemikaalien hintatietoja

\begin{tabular}{|l|r|l|}
\hline käyttöhyödyke & \multicolumn{1}{|l|}{ hinta } & viite \\
\hline sähkö & $0,094 € / \mathrm{kWh}$ & www.sahkonhinta.fi (27.10.2015) \\
\hline $\mathrm{H}_{2} \mathrm{SO}_{4}(93 \%)$, maatilamittakaava & $0,30 € / \mathrm{kg}$ & $\begin{array}{l}\text { suullinen tiedonanto (28.8.2015): } \\
\text { Eljas Jokinen, Koneta Agriculture Oy }\end{array}$ \\
\hline $\mathrm{HNO}_{3}(68 \%)$, maatilamittakaava & $0,60 € / \mathrm{kg}$ & $\begin{array}{l}\text { arvioitu } \\
\text { hintatietojen perusteella }\end{array}$ \\
\hline $\mathrm{NaOH}(99 \%)$, maatilamittakaava & $0,89 € / \mathrm{kg}$ & $\begin{array}{l}\text { arvioitu www.alibaba.com }(27.11 .2015) \\
\text { hintatietojen perusteella }\end{array}$ \\
\hline
\end{tabular}

Kannattavuuslaskelmiin valittiin tehdyistä kokeista kaksi viimeisintä, jotka antoivat parhaan erotustehokkuuden (Kuva 2). Näiden perusteella pilot-kokeissa käytettyä aerobisesti käsiteltyä sian lietelannan nestejaetta olisi tarvittu 4061 (NH4-N pitoisuus 1,24 g/l) valmistamaan 30,1 1 väkevöityä ammoniumsulfaattiliuosta (NH4-N pitoisuus $15,3 \mathrm{~g} / \mathrm{l})$. 


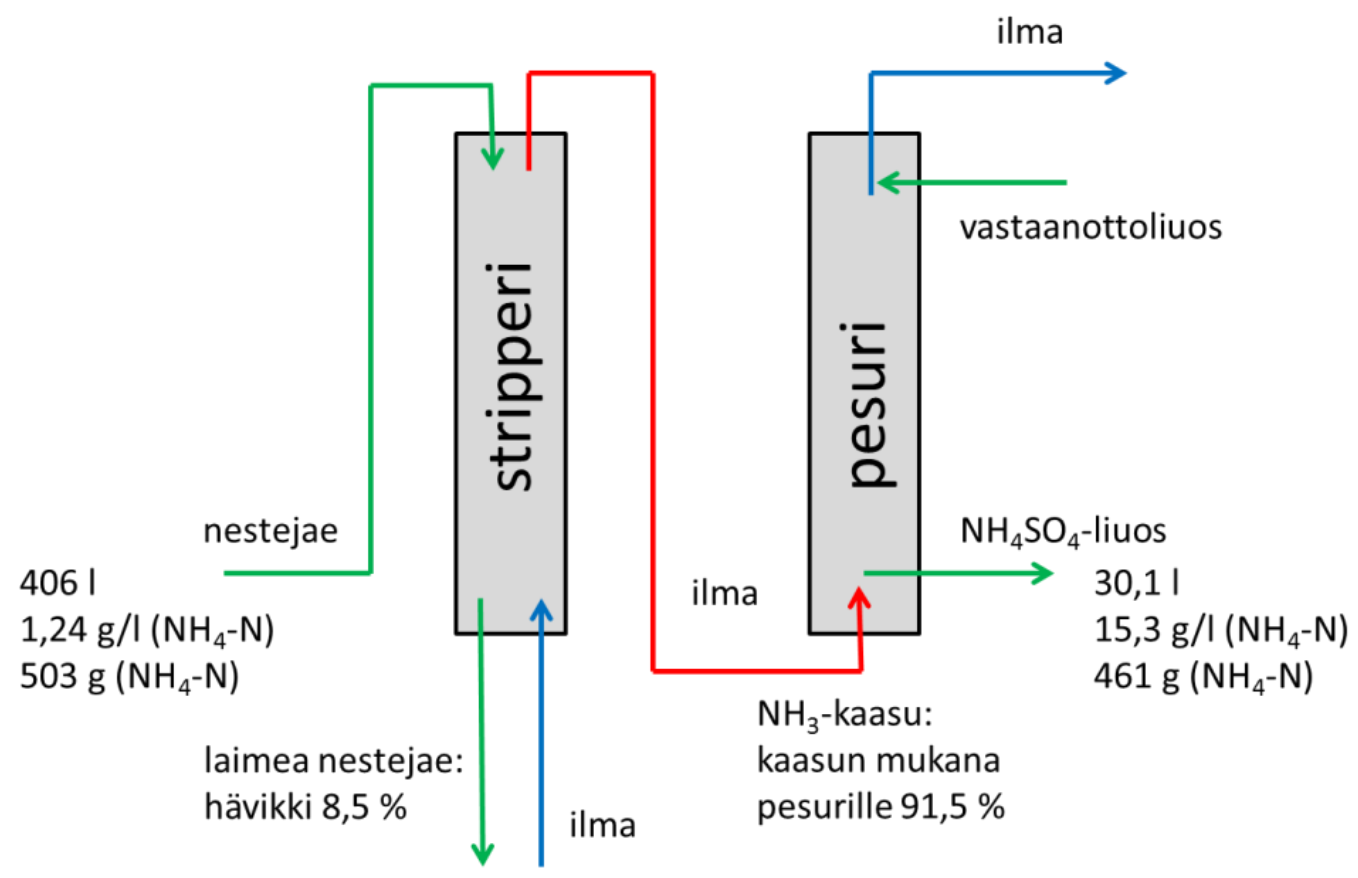

Kuva 2. Ilma- ja nestevirtaamat stripperi- pesurisysteemissä ja ammoniumtypen tase.

Koeajoissa kului keskimäärin energiaa lämmitykseen 0,00126 kWh/l/aste. Nestejaetta (406 l) lämmitettiin lämpötilasta $21,5^{\circ} \mathrm{C}$ lämpötilaan $39,8^{\circ} \mathrm{C}$, jolloin lämmitykseen kului energiaa $9,4 \mathrm{kWh}$ (Taulukko 3 ).

Taulukko 3. Ammoniumsulfaatin valmistuskustannus

\begin{tabular}{|c|c|c|c|}
\hline Esikäsittely & kWh & $€ / \mathbf{k W h}$ & $€$ \\
\hline Lämmitys & 9,4 & 0,094 & 0,88 \\
\hline & kg & $€ / \mathrm{kg}$ & $€$ \\
\hline $\begin{array}{l}\text { pH:n säätö } \\
(\mathrm{NaOH} 99 \%)\end{array}$ & 2,4 & 0,89 & 2,18 \\
\hline $\begin{array}{l}\text { Ammoniakin } \\
\text { strippaus }\end{array}$ & kWh & $€ / \mathbf{k W h}$ & $€$ \\
\hline $\begin{array}{l}\text { Syöttöpumppu } \\
\text { (nestejae) }\end{array}$ & & & \\
\hline Puhallin & yhteinen mittaus & & \\
\hline Ammoniakin pesu & kWh & $€ / \mathbf{k W h}$ & $€$ \\
\hline $\begin{array}{l}\text { Syöttöpumppu } \\
\text { (vastaanottoliuos) }\end{array}$ & 12,0 & 0,094 & 1,12 \\
\hline & kg & $€ / \mathbf{~ k g}$ & $\epsilon$ \\
\hline $\begin{array}{l}\text { Vastaanottoliuos } \\
\left(\mathrm{H}_{2} \mathrm{SO}_{4} 93 \%\right)\end{array}$ & 1,7 & 0,30 & 0,52 \\
\hline $\begin{array}{l}\text { Kemikaali- ja } \\
\text { energiakulut yht. }\end{array}$ & & & $\begin{array}{r}€ \\
4,70 \\
\end{array}$ \\
\hline $\begin{array}{l}\text { Lopputuotteen saanto } \\
\left(\mathrm{NH}_{4}-\mathrm{N}\right) \\
\text { Tuotantokustannus }\end{array}$ & $\begin{array}{r}\mathbf{l} \\
30,1\end{array}$ & $\begin{array}{l}\mathbf{g} / \mathbf{l} \\
15,3\end{array}$ & $\begin{array}{r}\mathbf{g} \\
461 \\
\boldsymbol{\epsilon} / \mathbf{k g ~ N H}_{\mathbf{4}}-\mathrm{N} \\
\mathbf{1 0 , 2 1} \\
\end{array}$ \\
\hline
\end{tabular}


Ammoniakin strippauksessa käytetyn pumpun (nestejakeen pumppaus) ja puhaltimen sekä pesussa käytetyn pumpun (vastaanottoliuoksen pumppaus) yhteinen sähkönkulutus mitattiin. Kahdessa viimeisessä koeajossa sähkönkulutus oli $0,0295 \mathrm{kWh} / 1$ käsiteltyä nestejaetta, jolloin 4061 nestejaetta kohti sähköä kului $12,0 \mathrm{kWh}$.

Koeajoissa käytetyn aerobisesti käsitellyn sian lietelannan $\mathrm{pH}$ oli alussa 8,4. Kahdessa viimeisessä koeajossa se nostettiin $\mathrm{pH} 11,3$ lisäämällä $50 \% \mathrm{NaOH}$-liuosta $1,2 \%$ nestevirtauksesta. Edullisinta on ostaa $\mathrm{NaOH} 99 \%$ hiutaleina. Kulutus hiutaleina olisi vastaavasti ollut 2,4 kg.

Rikkihapon kulutus laskettiin ammoniumsulfaatin saannon perusteella. Kun lopputuotteeksi saadaan 30,1 1 ammoniumsulfaattia, jonka typpipitoisuus on 15,3 g/l, on muodostuneen ammoniumsulfaatin määrä $461 \mathrm{~g}$. Moolimassojen avulla laskettuna $93 \% \mathrm{H}_{2} \mathrm{SO}_{4}$-liuoksen menekki on tällöin 1,7 kg.

Tuotantokustannukseksi kierrätystyppilannoitteelle saatiin pilot-mittakaavassa $10,20 € / \mathrm{kg} \mathrm{NH}_{4}-\mathrm{N}$. Teollisessa mittakaavassa sekä energia- että kemikaalikustannuksissa on mahdollisuus säästää. Lämmitysenergiana voidaan käyttää esim. biokaasulaitoksen hukkalämpöä ja kemikaalien ostohinnat on mahdollista neuvotella edullisemmiksi kemikaalien kulutuksen kasvaessa. Teollisen mittakaavan tuotantokustannusten arvioitiin jäävän alle puoleen pilot-mittakaavan kustannuksista $(4,10 € / \mathrm{kg}$, laskentaa ei esitetty tässä). Kustannus on silti nelinkertainen mineraalityppilannoitteiden sisältämän typen hintaan nähden (0,95€/kg, https://portal.mtt.fi/portal/page/portal/kasper/pelto/peltopalvelut/fosforilaskuri, 1.6.2015).

Prosessin kannattavuutta onkin tarkasteltava typen poiston kannalta. Teollisessa prosessissa hyöty voidaan saavuttaa alentuneina jätevesimaksuina, kun jäteveden typpipitoisuus laskee. Prosessikustannusten avulla laskettiin hinta myös käsitellyn nestejakeen tilavuutta kohti. Teollisen mittakaavan kemikaali- ja energiahinnoilla nestejakeen $\left(1,24 \mathrm{~g} / \mathrm{l}, \mathrm{NH}_{4} \mathrm{~N}\right)$ käsittelykustannukseksi saatiin $4,60 € / \mathrm{m}^{3}$.

\section{Johtopäätökset}

Sian lietelannasta peräsin oleva neste soveltui käsiteltäväksi laitteistolla ja ammoniumtypen erotuksessa päästiin yli $90 \%$ :n erotustehokkuuteen. Ammoniakin erottumiseen vaikuttivat sekä pH että ilma/neste suhde; korkea $\mathrm{pH}$ ja suuri ilma/neste-suhde tehostivat ammoniakin erottumista.

Ammoniumsulfaatin valmistuksen minimituotantokustannus oli pilot-mittakaavan kokeissa korkea, $10,21 € / \mathrm{kg} \mathrm{NH}_{4}-\mathrm{N}$. Teollisessa mittakaavassa on mahdollista säästää sekä kemikaali- että energiakustannuksissa. Prosessin pääasiallinen hyöty saavutetaan kuitenkin pikemminkin nestejakeen typenpoistosta eikä kierrätyslannoitteen valmistuksesta.

\section{Kirjallisuus}

Alitalo, A. 2014. Combination of biological and physico-chemical factors in the development of manue nutrient recovery and recycling-oriented technology. Doctoral Thesis. MTT Science 29. MTT Agrifood Research Finland, Jokioinen, Finland. $156 \mathrm{~s}$.

Antikainen, R., Lemola, R., Nousiainen, J. I., Sokka, L., Esala, M., Huhtanen, P. \& Rekolainen, S. 2005. Stocks and flows of nitrogen and phosphorus in the Finnish food production and consumption system. Agriculture, Ecosystems and Environment 107: 287-305.

Cheung, K. C., Chu, L. M., \& Wong, M. H. 1997. Ammonia stripping as a pretreatment for landfill leachate. Water, Air, \& Soil Pollution, 94(1), 209-220.

Eurostat [www]. [viitattu 13.12.2015]. Saatavissa: http://ec.europa.eu/eurostat

Janus, H.M., \& Van der Roest H.F. 1997. Don't reject the idea of treating reject water. Water science and technology, vol 35, No 10, s. 27-34

Jardin, N., Thöle, D., Wett, B. 2006. Treatment of sludge return liquors: Experiences from the operation of fullscale plants. Teoksessa: Proceedings of the Water Environment Federation, WEFTEC 2006. Dallas, TX, USA. October 21-25, 2006

McCullough, H. 1967. The determination of ammonia in whole blood by a direct colorimetric method. Clinica Chimica Acta. 17, 297-304.

SFS 1990. SFS 3008, Veden, lietteen ja sedimentin kuiva-aineen ja hehkutusjäännöksen määritys. Suomen Standardoimisliitto ry, Helsinki. 